5. Mihaljevic S., Salopek-Sondi B. Alanine conjugate of indole-3-butyric acid improves rooting of highbush blueberries // Plant Soil and Environ. - 2012. - Vol. 58. - № 5. - P. 236-241. - ISSN: 1214-1178.

6. Ostrolucka M.G., G. Libiakova, E. Ondruskova, A. Gajdosova. In vitro propagation of Vaccinium species // Acta Universitatis Latviensis, Biology. - 2004. - Vol. 676 - P. 207-212. ISSN: 1407-2157.

7. Ruzić D., Vujović T., Cerović R., Ostrolucka M.G., Gajdosova A. Micropropagation in vitro of highbush blueberry (Vaccinium corymbosum L.) // Acta Horticulturae. - 2012. Vol. 926. - P. 265-272. - doi: 10.17660/ActaHortic.2012.926.36

\title{
EX VITRO ROOTING OF THE IN VITRO-DERIVED CRANBERRY PLANTS
}

\author{
Bazhydai T. N. \\ Republican Unitary Enterprise "Institute for Fruit Growing" \\ agro-town Samokhvalovichi, Republic of Belarus,e-mail: tanya_bozhidaj@mail.ru
}

In vitro-derived shoots of Vaccinium spp. plantlets are able to produce roots both in vitro and ex vitro. The aim of the research was to evaluate the influence of substrates on ex vitro rooting and morphological parameters of cranberry regenerants ('Stevens', 'McFarlin', 'Ben Lear'). The following acclimatization substrates were tested: moss Sphagnum L. with upper layer of acid peat $(0.5 \mathrm{~cm})$; acid peat with upper layer of perlite $(0.5 \mathrm{~cm})$; acid peat; moss Sphagnum L. with upper layer of perlite $(0.5 \mathrm{~cm})$. It was found that moss with upper layer of acid peat was the most suitable substrate for ex vitro rooting of cranberry cv. Stevens and cv. Ben Lear, moss with upper layer of perlite or acid peat - for ex vitro rooting of cranberry cv. McFarlin.

Key words: cranberry, rooting, ex vitro, acid peat, moss Sphagnum L., perlite, Belarus.

УДК 631.526:57.085.2

\section{ИЗУЧЕНИЕ ОСОБЕННОСТЕЙ \\ СОМАТИЧЕСКОГО ЭМБРИОГЕНЕЗА ПРЕДСТАВИТЕЛЕЙ РОДА ВЕGONIA L. В КУЛЬТУРЕ IN VITRO}

\author{
Малаева Е. В. ${ }^{1,2}$ \\ ${ }^{1}$ Государственное бюджетное учреждение \\ «Волгоградский региональный ботанический сад» \\ ${ }^{2}$ Федеральное государственное бюджетное \\ образовательное учреждение высшего профессионального образования \\ «Волгоградский государственный социально-педагогический университет» \\ 2. Волгоград, Россия, e-mail: e.malaeva@mail.ru
}

Приведены результаты исследований морфогенеза в культуре in vitro эксплантов $B$. bowerae 'Nigramagra', B. bowerae 'Pink Perfection', B. hybrida 'Bonita Shea', B. masoniana Irntsch., B. imperialis 'Otto forster' для разработки способов 
Субтропическое и декоративное садоводство (65)

клонального микроразмножения исследуемых сортов. Выявлены типы и размеры эксплантов, зависимость морфогенетических реакций от генотипа. Установлены особенности гормональной регуляции морфогенеза in vitro. Изучено влияние кинетина и 6-БАП на формирование соматических эмбриоидов.

Ключевые слова: бегония, соматический эмбриогенез, органогенез, морфогенез, in vitro, клональное микроразмножение.

Род Begonia L. включает более 1000 видов растений [9]. Более 120 видов бегоний используются в декоративном садоводстве [8]. Различные виды данного рода также очень популярны в комнатном озеленении.

На основе B. rex Putz., B. cucullata Willd., B. heracleifolia Cham. \& Schltdl., B. bowerae (boweri) Ziesenh. создано около 10000 гибридов и культиваров, используемых для озеленения в открытом и закрытом грунте. Некоторые бегонии известны как лекарственные растения в народной медицине. Получены данные о фитонцидных свойствах бегоний, что обуславливает актуальность их применения для фитодизайна помещений различного назначения [3].

Разнообразие жизненных форм и морфологических признаков листа в сочетании с фитонцидной активностью многих видов бегонии обуславливают перспективность их использования для озеленения интерьеров различного назначения [6]. Однако возникающие трудности при традиционном размножении в процессе сохранения коллекций в ботанических садах заставляют учёных обращаться к современным методам биотехнологии растений.

Существует ряд работ по изучению прямой и непрямой регенерации бегонии в условия in vitro $[2,7]$.

Однако морфогенетические потенции органов и тканей различных видов и сортов растений в условиях in vitro существенно отличаются. Поэтому исследования, направленные на изучение процессов органогенеза и эмбриогенеза в условиях in vitro B. masoniana Irmsch. ex Ziesenh. и гибридов $B$. bowerae Ziesenh., являются весьма актуальными, так как позволяют пополнить знания об особенностях морфогенеза растений в целом, разработать методологию получения и сохранения ценных видов и сортов растений.

В связи с этим целью работы являлось изучение путей регенерации представителей рода Begonia в культуре in vitro через органогенез и соматический эмбриогенез из листовых эксплантов.

Объекты и методы. Коллекция рода Begonia ГБУ ВО «Волгоградский региональный ботанический сад» насчитывает 54 вида и сорта. После проведения ретроспективного анализа коллекций были выбраны 
Глава 4. Биотехнология растений

следующие представители, которые пользуются наибольшей популярностью в комнатном озеленении: B. bowerae 'Nigramagra', $B$. bowerae 'Pink Perfection, B. hybrida 'Bonita Shea', B. masoniana, B. imperialis 'Otto forster'.

Методика исследований базировалась как на общепринятых классических приёмах с культурами изолированных тканей и органов растений [1], так и на методах, разработанных в лаборатории биотехнологии ГБУ ВО «ВРБС» [4].

Для обеспечения максимальной генетической стабильности клонируемого материала и во избежание аномалий мы использовали молодые растения возрастом 2-3 года. После отделения от цельного растения листовые экспланты тщательно отмывались с помощью моющих средств и в течение 1-1,5 часа находились под проточной водой.

В качестве исходных эксплантов мы использовали листовые экспланты 5 видов и сортов бегонии, размером 1,5 × 1,5 см, без видимых повреждений.

Стерилизацию эксплантов проводили с помощью различных хлорсодержащих стерилизующих агентов с различным временем экспозиции. Оптимальный режим стерилизации определяли по жизнеспособности первичных эксплантов и наличию инфекции.

После растительные экспланты стерилизовались. Листья предварительно обрабатывали 95 \%-ным этиловым спиртом в течение 50-60 секунд.

В качестве стерилизатора использовали различные концентрации Хлорамина (действующее вещество - натриевая соль хлорамида бензосульфокислоты) и Лизоформина (действующее вещество - глутаровый альдегид, глиоксаль и дидецилдиметиламмоний хлорид), а также раствор бытовой белизны с различной экспозицией.

При изучении особенностей клонального микроразмножения бегонии использовали питательные среды по прописи Мурасиге и Скуга [10].

Для регулирования регенерационных процессов бегонии in vitro в питательную среду добавляли 6-бензиламинопурин (6-БАП), кинетин (К), тидиазурон (TDZ), $\alpha$-нафтилуксусную кислоту (НУК), индолил-3-уксусную кислоту (ИУК), $\beta$-индолил-3-масляную кислоту (ИМК). В экспериментах по изучению особенностей соматического эмбриогенеза бегонии в культуре in vitro использовали модификации питательных сред, содержащие от 0,1 до 0,5 мг/л К и 6-БАП в сочетании с НУК в концентрации от 0,1 до 1,5 мг/л.

В условиях in vitro растения культивировали в чашках Петри и пробирках при освещении с интенсивностью 3-5 клк, при 16-часовом фотопериоде, температуре $24{ }^{\circ} \mathrm{C}$ и относительной влажности воздуха $70 \%$ и в условиях термостата: температура $25^{\circ} \mathrm{C}$, без освещения. 
Субкультивирование велось в течение 35 дней, по окончании которого учитывали количество регенерировавших микропобегов с одного экспланта, количество укоренённых микропобегов, среднюю длину и число корней. На этапе адаптации рассчитывали выход растений регенерантов. Все опыты проводились в трёхкратной повторности, количество вариантов в каждой повторности составляло 10 пробирок.

Результаты экспериментальных данных обрабатывались статистически с помощью компьютерной программы Excel, лицензионного пакета Microsoft Office 2007.

Результаты. Для введения в культуру in vitro были отобраны листья взрослых растений в период с мая по август. Было установлено, что листья, отобранные с мая по июнь, были наиболее морфогенными, и частота образования соматических зародышей достигала 70-92 \%. В последующие месяцы этот показатель значительно снижался, что соответствует ряду литературных данных $[5,7]$. У листьев, собранных в декабре, морфогенность была наименьшей и составила - $30 \%$.

В настоящее время разработаны и используются различные схемы стерилизации в зависимости от специфики культуры и типа экспланта.

Для получения стерильной культуры бегонии использовали лизоформин, хлорамин и гипохлорид натрия в составе белизны в различных концентрациях. Результаты проведённых экспериментов представлены в таблице 1 .

Оптимальным стерилизующим агентом для всех исследованных сортов бегонии является 7\%-ный лизоформин, экспозиция 10 мин, и 10\%-ная белизна, экспозиция 15 мин. Использование лизоформина в более высоких концентрациях нецелесообразно, так как наблюдали некроз тканей эксплантов, что значительно снижало их морфогенетический потенциал и последующую частоту регенерации микропобегов.

В процессе исследования был модифицирован состав питательной среды МС и подобраны оптимальные концентрации фитогормонов для индукции морфогенетических процессов в тканях листа, приводящих к соматическому эмбриогенезу. Нами было отмечено, что использование TDZ стимулировало образование рыхлого каллуса по всему периметру высечки листа. Для формирования соматических эмбриоидов весьма эффективным является использование различных концентраций К в сочетании с НУК. При этом отмечена оптимальной концентрация $\mathrm{K}-0,5$ мг/л, где формировались соматические зародыши на 62 и 59 и 40 \% листовых дисков у сортов B. hybrida 'Bonita Shea', $B$. bowerae 'Nigramagra' и $B$. masoniana соответственно.

Дальнейшее повышение концентрации кинетина и 6-БАП индуцировало активное каллусообразование и уменьшало количество эксплантов, способных к соматическому эмбриогенезу. 
Глава 4. Биотехнология растений

Таблиия 1

Выход жизнеспособных эксплантов

B. bowerae 'Nigramagra' в зависимости от режима стерилизации

\begin{tabular}{|c|c|c|c|c|}
\hline \multirow{2}{*}{$\begin{array}{c}\text { Действующее } \\
\text { вещество }\end{array}$} & $\begin{array}{c}\text { Концентрация } \\
\text { стерилизующего } \\
\text { агента, } \\
\%\end{array}$ & \multicolumn{3}{|c|}{ Количество } \\
\cline { 2 - 5 } & $\mathbf{2}$ & 5 мин & 10 мин & 15 мин \\
\hline \multirow{3}{*}{ Лизоформин } & 5 & $46 \pm 2,1$ & $52 \pm 2,7$ & $45 \pm 2,8$ \\
\cline { 2 - 5 } & 7 & $80 \pm 4,3$ & $91 \pm 2,6$ & $38 \pm 1,7$ \\
\cline { 2 - 5 } & 10 & $29 \pm 2,5$ & $18 \pm 1,6$ & некроз \\
\hline \multirow{3}{*}{ Хлорамин } & 5 & $27 \pm 2,7$ & $42 \pm 3,1$ & $49 \pm 2,9$ \\
\cline { 2 - 5 } & 7 & $38 \pm 2,1$ & $46 \pm 2,3$ & $48 \pm 3,0$ \\
\hline \multirow{2}{*}{\begin{tabular}{c} 
Гипохлорид \\
натрия в соста- \\
\cline { 2 - 5 } ве белизны
\end{tabular}} & 10 & $44 \pm 2,7$ & $50 \pm 2,0$ & $51 \pm 2,5$ \\
\cline { 2 - 5 } & 5 & $31 \pm 2,7$ & $35 \pm 2,1$ & $36 \pm 2,7$ \\
\hline
\end{tabular}

Вычленяя высечки листа размером 1,5 × 1,5 см из разных зон листовой пластинки и помещая их на питательную среду, удалось определить наиболее морфогенные зоны, способные к соматическому эмбриогенезу. Это зоны соединения листовой пластинки с черешком и край высечки листа (рис. 1а).

Для индукции формирования соматических зародышей высечки листа помещали в термостат с температурой $25^{\circ} \mathrm{C}$ в отсутствии освещения и в культуральную комнату с температурой $24{ }^{\circ} \mathrm{C}$ и освещённостью 5 000-6 000 Лк при 16-часовом фотопериоде.

В процессе исследования было установлено, что путь реализации морфогенетического потенциала эксплантов зависел от условий культивирования. В условиях термостата у эмбриоидов активно формировались корни, в количестве 2-3 шт. (рис. 1б).

На свету происходило три морфогенетических процесса:

1. прямой соматический эмбриогенез, на питательной среде MS К 0,5 мг/л + НУК 1,5 мг/л, в термостате при температуре $25{ }^{\circ} \mathrm{C}$;

2. непрямой соматический эмбриогенез, при котором высечки листа культивировались на питательной среде MS 6-БАП 0,5 мг/л + НУК 0,5мг/л, на свету. Экспланты образовывали каллус, в котором затем начинался процесс образования соматических зародышей;

3. прямая регенерация микропобегов на среде MS 6-БАП 0,5 мг/л + НУК 0,1 мг/л, на свету. 

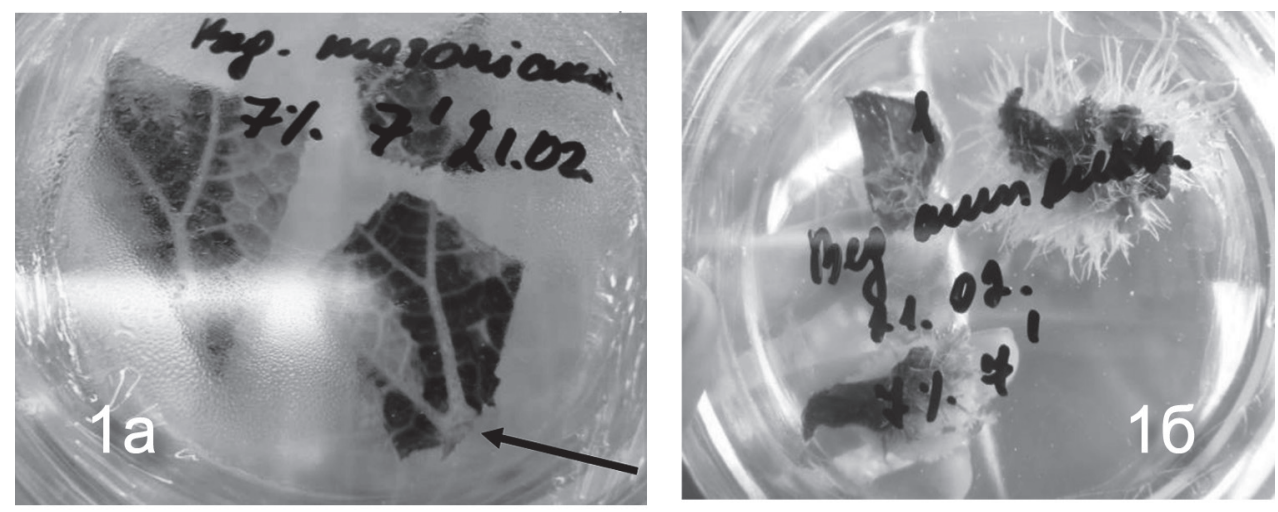

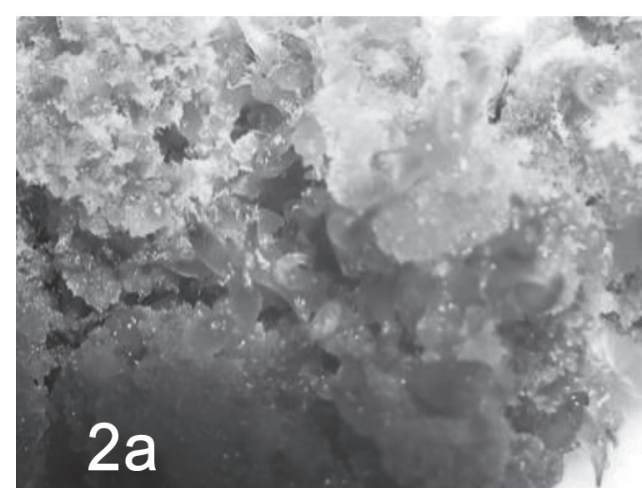

Рис. 1а. Зоны листовой пластинки B. masoniana, способные к морфогенезу в условиях in vitro

Рис. 2а. Образование соматических эмбриоидов из каллуса на питательной среде MS 6-БАП 0,5 мг/л + НУК 0,5мг/л

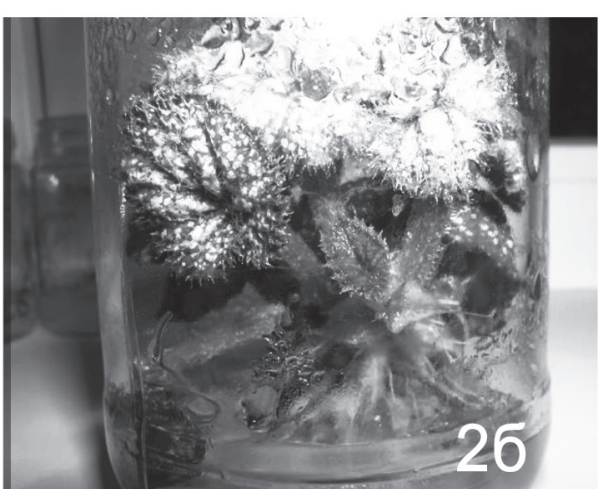

Рис. 1б. Развитие корней у соматических зародышей B. imperialis 'Otto forster' при культивировании в темноте

Рис 2б. Растения бегонии перед высадкой на адаптацию in vivo

В течение последующих 30 суток наблюдали развитие полноценных соматических зародышей (рис. 2a). В присутствии К в питательной среде в концентрации 0,5 мг/л и 1,5 мг/л НУК среднее количество соматических эмбриоидов на эксплант достигало $62 \%$ для B. hybrida 'Bonita Shea' и 40 \% для B. masoniana (табл. 2).

В процессе исследований было отмечено, что на среде 1 растения развивались очень медленно, поэтому для массового образования растений из эмбриоидов концентрацию НУК уменьшали до 0,1 мг/л. При этом формировались полноценные растения. 
Глава 4. Биотехнология растений

Образование соматических зародышей в эмбриогенном каллусе также происходило на питательной среде 2. При этом для эмбриоидов была характерна более зелёная окраска. На среде одновременно появлялись новые эмбриоиды и развивались растения, которые можно адаптировать in vivo.

Таблиияа 2

Образование соматических

зародышей в культуре листовых дисков бегонии

\begin{tabular}{|c|c|c|c|c|}
\hline \multirow{2}{*}{$\begin{array}{c}\text { Вариант } \\
\text { питательной } \\
\text { среды }\end{array}$} & \multicolumn{4}{|c|}{ Количество эксплантов с соматическими эмбриоидами, \% } \\
\hline & $\begin{array}{l}\text { B. hybrida } \\
\text { 'Bonita Shea' }\end{array}$ & $\begin{array}{l}\text { B. bowerae } \\
\text { 'Nigramagra' }\end{array}$ & B. masoniana & $\begin{array}{l}\text { B. imperialis } \\
\text { 'Otto forster' }\end{array}$ \\
\hline 1 & $62 \pm 1,0$ & $59 \pm 0,9$ & $40 \pm 1,0$ & $52 \pm 1,3$ \\
\hline 2 & $40 \pm 0,8$ & $38 \pm 0,7$ & $18 \pm 1,4$ & $27 \pm 0,4$ \\
\hline 3 & 0 & 0 & 0 & 0 \\
\hline
\end{tabular}

Примечание:

1 - MS K 0,5 мг/л + НУК 1,5 мг/л - прямой соматический эмбриогенез;

2 - MS 6-БАП 0,5 мг/л + НУК 0,5мг/л - непрямой соматический эмбриогенез;

3 - MS 6-БАП 0,5 мг/л + НУК 0,1 мг/л - прямая регенерация

Растения бегонии для микроразмножения помещали на питательную среду MS с различным содержанием цитокининов и их сочетание с ауксинами с целью массового размножения. Сравнительный анализ полученных данных показал, что максимальный коэффициент размножения наблюдался при использовании сочетания цитокинов и ауксинов БАП 0,5 ИУК 0,1 для всех видов и сортов бегонии (рис. 3).

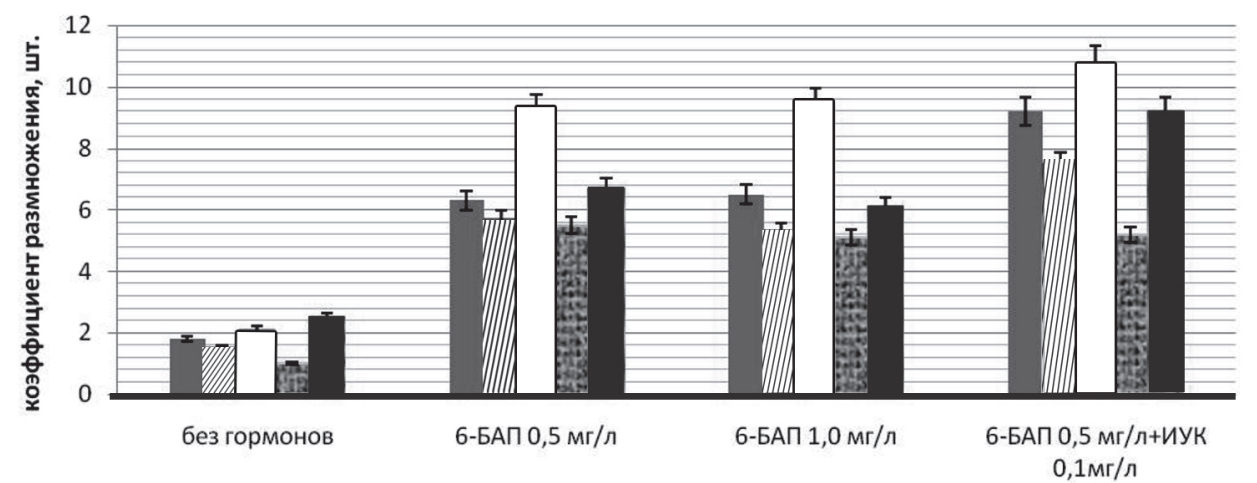

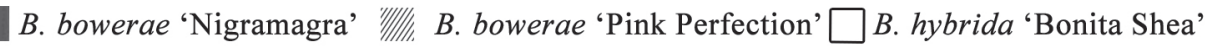
酮 B. masoniana Irntsch.

B. imperialis 'Otto forster'

Рис. 3. Влияние гормонального состава питательной среды на коэффициент размножения бегонии 
Было выявлено, что на питательной среде, содержащей 6-БАП в концентрации 0,5 мг/л и ИУК 0,1 мг/л, коэффициент размножения был максимальным: $10,8 \pm 1,0$ для B. hybrida 'Bonita Shea'. Кроме того, данная модификация питательной среды способствовала спонтанному образованию корней, которое достигало 90-100 \%, что экономически весьма эффективно, так как позволяет сократить этап укоренения in vitro.

Для укоренения бегонии в культуре in vitro лучшие показатели наблюдали с ИУК по сравнению с ИМК. Сравнительный анализ данных показал, что оптимальным является использование ИУК в концентрации 0,5 мг/л. При этом процент укоренения в среднем составил 70 \% и среднее количество корней на эксплант - 4-5 шт.

Адаптация размноженных in vitro растений бегонии проводили с использованием смеси песка, торфа и листовой земли в соотношении $1: 1: 1$. Выход адаптированных растений составил 70 \%. Весьма эффективным на стадии адаптации является использование замены листовой земли на перлита или вермикулит, что увеличило выход адаптированных растений до $85 \%$.

Выводы. В результате проведённых исследований нами установлены оптимальные сроки отбора листьев бегонии (май-июнь) для введения в культуру in vitro. Оптимальным стерилизующим агентом для всех исследованных сортов бегонии является 7\%-ный лизоформин, экспозиция 10 мин, и 10\%-ная белизна, экспозиция 15 мин. При этом получено 91 \% эксплантов, свободных от контаминации. На основе изучения действия экзогенных факторов (кинетина и НУК) на реализацию морфогенетического потенциала высечек листа видов и сортов бегонии определены основные пути регенерации растений.

Среди указанных выше путей регенерации бегонии в культуре in vitro экономически эффективным является прямой соматический эмбриогенез и прямой органогенез, так как позволяют получить в среднем 12 и 19 растений из одного экспланта in vitro, а при традиционном вегетативном размножении 3-5 шт. с одного растения. В свою очередь непрямой соматический эмбриогенез позволяет получить новые формы бегоний с различными соматическими мутациями.

\section{Библиографический список}

1. Бутенко Р.Г. Биология клеток высших растений in vitro и биотехнология на их основе. - М.: ФБК-ПРЕСС, 1999. - 160 с. - ISBN: 5-89240-059-Х.

2. Иванова Н.Н., Митрофанова И.В., Митрофанова О.В. Методические основы клонального микроразмножения некоторых декоративных культур // Сборник научных трудов ГНБС. - 2014. - № 138. - С. 57-101. - ISSN: 0201-7997. 
3. Карпова Е.А., Цыбуля Н.В., Храмова Е.П., Якимова Ю.Л., Фершалова Т.Д. Антимикробная активность и содержание флавоноидов у некоторых представителей рода Begonia L., используемых в фитодизайне // Вопросы биологической, медицинской и фармацевтической химии. - 2011. - Т. 9. - № 1. - С. 8-16. - ISSN: 1560-9596.

4. Малаева Е.В., Молканова О.И. Биотехнологические и экономические аспекты клонального микроразмножения ремонтантной малины // Плодоводство и ягодоводство России. - 2017. - Т. 48. - № 2. - С. 183-189. - ISSN: 2073-4948.

5. Митрофанова И.В., Соколова М.К., Митрофанова О.В., Иванова Н.Н., Челомбит С.В. Биотехнологическая система получения растений каладиума (Caladium hortulanum Bridsey) через соматический эмбриогенез и органогенез // Сборник научных трудов ГНБС. - 2007. - № 127. - С. 50-60. - ISSN: 0201-7997.

6. Фершалова Т.Д., Байкова Е.В. Интродукция бегоний в оранжереях и интерьерах / отв. ред. акад. РАН И.Ю. Коропачинский. - Новосибирск: Гео, 2013. - 157 с. - ISBN: 978-5-906284-20-4.

7. Фершалова Т.Д., Набиева А.Ю. Способы размножения представителей рода Begonia L. в пролонгированной культуре // Успехи современного естествознания. - 2018. - № 1. - C. 56-61. - ISSN: 1681-7494.

8. Шахова Г.И. Бегонии. - М.: Кладезь-Букс, 2005. - С. 7-56.

9. Tebbit M.C. Begonias: cultivation, natural history and identification. - Portland: Timber Press, 2005. $-272 \mathrm{p}$.

10. Murashige T., Skoog F. A revised medium for rapid growth and bioassays with tobacco tissue cultures // Phsiol. Plant. - 1962. - Vol. 15. - № 3. - P. 473-497.

\title{
STUDYING SPECIAL FEATURES \\ IN SOMATIC EMBRYOGENESIS OF BEGONIA L. REPRESENTATIVES IN VITRO
}

\author{
Malayeva E. V. ${ }^{1,2}$ \\ ${ }^{l}$ State Budgetary Institution of Volgograd region \\ "Volgograd Regional Botanical Garden" \\ ${ }^{2}$ Federal State Budgetary Educational \\ Institution of Higher Professional Education \\ "Volgograd State Social \& Pedagogical University" \\ c. Volgograd,Russia,e-mail: e.malaeva@mail.ru
}

The paper studied morphogenesis in vitro for $B$. bowerae 'Nigramagra', $B$. bowerae 'Pink Perfection', B. hybrida 'Bonita Shea', B. masoniana Irmsch. ex Ziesenh., $B$. imperialis 'Otto forster' explants aiming to work out the methods of clonal micropropagation of the studied cultivars. Types and sizes of explants as well as dependence of morphogenetic capacity on the genotype were determined. The peculiarities of hormone regulation of morphogenesis in vitro were established. The influence of kinetin and 6-BAP concentration on somatic embryoid formation was investigated.

Key words: Begonia, somatic embryogenesis, organogenesis, morphogenesis, in vitro, clonal micropropagation. 